\title{
O PROBLEMA DA CRISE CAPITALISTA EM O CAPITAL DE MARX ${ }^{1}$
}

Bruno Gonçalves da Paixão

Em tempos da tão propalada crise no Brasil, um livro publicado em 2016 vem discutir exatamente o conceito de crise a partir de Marx. Esse livro é: O problema da crise em O Capital de Marx. Escrito pelos professores-pesquisadores Hector Benoit e Jadir Antunes e fruto de longos trabalhos conjuntos entre os dois.

O livro, de forma geral, procura contrapor as posições dominantes em torno do problema da crise em $O$ Capital de Marx, predominantemente vista pelo viés empiricista de "causa". Nesse sentido, à fragilidade imputada às concepções que procuram entender a crise a partir do mundo empírico, os autores contrapõem pela via conceitual do problema. Para os mesmos, a crise em O Capital só poderá ser compreendida caso o acento recaia sobre o conceito de crise, "a partir do modo de exposição (die Darstellungsweise)" (p. 24).

No primeiro capítulo, os autores vão mostrar como a noção de crise em Marx perpassa sua exposição já a partir do Livro Primeiro e de forma interna à explanação sobre o processo de produção de mais-valia. Nesse sentido, vão argumentar os autores que, na seção I de $O$ Capital, a representação da "circulação simples de mercadorias = M - D - M (Mercadoria - Dinheiro - Mercadoria)" (p. 41), reflete o momento abstrato e positivo da exposição, pois a partir dessa relação uma névoa ainda paira sobre o modo de produção capitalista, forçando um entendimento equivocado de equivalência nas trocas, e "a crise aparece em sua forma meramente formal". Já na seção II (sempre de $O$ Capital), o momento negativo começa a despontar a partir da análise da relação geral contraditória do capital ( $\mathrm{D}-\mathrm{M}-\mathrm{D}^{\prime}$ = Dinheiro - Mercadoria - mais-Dinheiro). Diferentemente da seção anterior o dinheiro surge como dinheiro "[...] como valor que deve se valorizar na circulação" (p.42). O porém, nessa situação, é explicar como o dinheiro se torna mais dinheiro e é aí que entra em cena a figura do operário e sua mercadoria (FT: força de trabalho).

As seções III a VI são, segundo os autores, "o segundo momento crítico e negativo da exposição e a primeira negação determinada do começo” (p. 43). Isso porque, ao chegar à fábrica capitalista, a relação onde o dinheiro se torna capital é desvelada enquanto extração de mais-valia daquela peculiar mercadoria chamada força

\footnotetext{
${ }^{1}$ Hector Benoit, Jadir Antunes. Jundiaí, SP: Paco Editorial, 2016, 212 p.

${ }^{2}$ Doutorando em Filosofia pelo PPGFIL da Universidade Estadual do Oeste do Paraná - UNIOESTE e membro associado do Instituto Lukács. E-mail: brunog.paixao@gmail.com.
} 
de trabalho do operariado. Aqui a crise se mostra como nascente da relação antípoda entre capital e trabalho. Neste ponto a pseudo relação de equivalência entre essas duas forças (C x T) é negada pela mais-valia. Na seção VII os autores mostram como toda a relação anterior se torna um círculo vicioso, onde o dinheiro se converte cada vez mais em mais dinheiro a partir da exploração do operariado, que retorna à circulação em forma de dinheiro se convertendo depois em mais força de trabalho e meios de produção, que por sua vez geram mais "mais-dinheiro", mantendo uma lógica perversa de exploração do proletariado. Assim, segundo Benoit e Antunes, “a crise aparece em suas formas mais concretas e explosivas” (p. 45). Agora já não é negada somente a falsa relação de equivalência nas trocas, mas "agora é negada a própria troca entre capital e trabalho" (p. 45). Após essas explanações é necessário caminhar para o terreno da história (Cap. XXIV: Acumulação originária), quebrando assim (no modo expositivo) o círculo vicioso comentado acima.

Nessa parte Marx volta às origens do capitalismo para mostrar que toda essa relação desenvolvida nas seções anteriores é pautada "na mais bárbara violência dos homens sobre os próprios homens" (p. 46). Aqui, sempre segundo Benoit e Antunes, o proletariado ganha corpo enquanto classe universalmente revolucionária. Assim, defendem os autores, que nessa "seção, a crise é finalmente resolvida e abolida pela tomada do poder pelo proletariado e pela instauração de uma economia socialista planificada" (p. 46).

Após analisar a crise a partir do método expositivo no Livro Primeiro de $O$ Capital, Benoit e Antunes passam a desvelar o aparecimento da crise no processo de circulação e realização da mais-valia, ou seja, o problema da crise no Livro Segundo. Nesse, um dos momentos possíveis de crise está imbricado ao processo de valorização do capital industrial, que se desdobra em "capital-monetário, capital-produtivo e capitalmercadoria" (p.100). Nessa acepção, "a possibilidade de uma crise e interrupção brusca da reprodução do capital surge da possibilidade de uma forma funcional não se converter na forma seguinte com a mesma regularidade e velocidade habituais" (p. 100). Em síntese, a crise poderá surgir caso as mercadorias não possam ser vendidas pelos capitalistas.

Nesse sentido, os autores vão destacar as crises de superprodução: "enquanto uma onda de mercadorias procura chegar rapidamente até a esfera do consumo, novas e gigantescas ondas são continuamente lançadas atrás dela” (p. 102). O problema é que,

\begin{tabular}{|l|l|l|l|l|}
\hline Q Povista Dialectus & Ano 4 & n. 10 & Janeiro - Julho 2017 & p. 265-269 \\
\hline
\end{tabular}


com um número grande de mercadorias, os estoques do mediador (p. ex. comprador atacadista da mercadoria) ficam abarrotados e esses não veem por que comprar mais, parando por um momento os pedidos junto à fábrica capitalista. Por um tempo, esse mediador poderá manter normalmente seu processo de enriquecimento, enquanto a fábrica começa a entrar em crise. Mas se a fábrica entra em crise, os primeiros a sentirem o efeito são os operários. E esses, desempregados, são sinal de menos dinheiro direcionado às compras finais da mercadoria. Ou seja, em algum momento, a crise atinge a todos. Dizem os autores que "o primeiro ciclo a ser interrompido pela crise será o ciclo do capital-mercadoria. Somente mais tarde a crise propagar-se-á para a esfera da circulação geral da mercadoria" (p. 106).

Benoit e Antunes chamam atenção mais uma vez sobre o caráter fortemente abstrato em que, até o momento, são tratadas as contradições internas do capital, evidenciando assim também, o caráter abstrato das crises. Ou seja, em toda a discussão do Livro Primeiro e Segundo, a crise só aparece como possibilidade. Assim, vão argumentar que "a superação das abstrações [...] só pode ser realizada na mesma medida em que colocarmos sob análise não mais o capital em sua generalidade abstrata, mas, sim, o capital em sua realidade concreta, o capital enquanto pluralidade de capitais" (p. 121).

A partir daí os autores entram no terceiro e último momento do livro, e o fazem exatamente tratando do capital em sua realidade mais concreta, ou no que dá no mesmo, em sua forma mais determinada, enveredando assim pelo caminho complexo do Livro Terceiro de $O$ Capital. A análise agora é sobre o processo total da produção capitalista.

Primeiramente, os autores vão mostrar como se processa a mistificação burguesa da transmutação da mais-valia às sagradas categorias de lucro e taxa de lucro. Ou seja, a relação em que o lucro do capitalista é vista por esses como algo autônomo, oriundo, de forma mágica, do próprio capital. Entendido dessa maneira é apagado qualquer vestígio da real relação, onde o trabalho é o gerador desse "lucro". Assim, argumentam Benoit e Antunes, “a mais-valia aparecerá como um valor adicional posto pelo gênio [...] capitalista prático e não como trabalho não pago extorquido do trabalhador" (p. 132). Isto é, "o lucro e a taxa de lucro são formas ilusórias da economia política do capital" (p. 139), para esconder que sua origem está na extração do trabalho não pago ao trabalhador.

\begin{tabular}{|l|l|l|l|l|}
\hline Q Rovista Dialectus & Ano 4 & n. 10 & Janeiro - Julho 2017 & p. 265-269 \\
\hline
\end{tabular}


Ao passarem para a seção III do Livro Terceiro a hipótese central do livro ganha corpo ao se deparar com uma tese dominante entre os economistas, inclusive, os marxistas: a de que a queda tendencial da taxa de lucro seria a causa da crise capitalista. Nessa parte, a exposição tenta mostrar todas as possíveis contradições do sistema do capital. E inerentes a essas contradições, a possibilidade real da crise. O nível denso da seção e a complexidade das contradições são didaticamente apresentados, possibilitando ao leitor entrar no mundo das fórmulas menos simples de O Capital, assim como, acompanhar o emaranhado de possíveis vias em que a queda da taxa de lucro pode se dá, não porque se perde em produtividade, mas pelo contrário, pelo aumento da produtividade. Ancorados em Marx, citam-no: "a taxa de lucro não cai porque o trabalho se torna mais improdutivo, mas porque se torna mais produtivo" (p. 168). Ora poderíamos argumentar grosseiramente - mas se o trabalho é quem gera o "lucro", como o aumento dele pode possibilitar uma queda e não um aumento do "lucro"? As variações exemplificadas pelos autores são muitas. Uma delas é que se mesmo numa relação onde o capital variável (força de trabalho) numa fábrica $x$, seja maior que na fábrica y, gerando assim uma taxa maior de mais-valia, a taxa de lucro pode ser menor em x que y caso em x o volume aplicado em capital constante seja bem maior que em y. Nesse sentido, vão afirmar os autores que a "taxa de lucro tende a cair, porque o elemento vivo criador da mais-valia é substituído [...] por capital constante que não valoriza o valor" (p. 177). E arrematam em torno da tese central que "as crises capitalistas emanam assim, não de uma ou outra contradição em particular, da superprodução relativa ou absoluta [...] do subconsumo, da queda na taxa de lucro etc., mas, sim, da totalidade contraditória e explosiva do capital” (p. 184). Ou seja, o capital gera, pela sua própria lógica constitutiva, as possibilidades da crise.

Ao finalizar, chamam atenção para o fato de que a interpretação corrente no texto, não se dá por mera volição ou vaidade quando se contrapõe às leituras causais da crise. Essas últimas, segundo Benoit e Antunes, destroem "o caráter programático, político e revolucionário de O Capital” (p. 203), e asseveram que "é este caráter dialético e revolucionário da obra de Marx [...] que procuramos recuperar nesta obra" (p. 203).

Essa breve apresentação geral do livro em questão não retrata uma parte infinitesimal da riqueza e precisão categorial em torno da problemática da crise em $O$ Capital, trazidas pelos professores-pesquisadores Benoit e Antunes. Isso quer dizer que,

\begin{tabular}{|l|l|l|l|l|}
\hline Q Povista Dialectus & Ano 4 & n. 10 & Janeiro - Julho 2017 & p. 265-269 \\
\hline
\end{tabular}


o leitor interessado que for se debruçar sobre esse livro, mergulhará na totalidade dos temas mais caros da monumental e mais importante obra de Marx. A relevância e originalidade da tese presente no livro, são da estatura de possíveis polêmicas que possam gerar. $\mathrm{O}$ que a torna tão instigante quanto necessária para o debate sobre a crise capitalista em $O$ Capital.

\begin{tabular}{|l|l|l|l|l|}
\hline Qevista Dialectus & Ano 4 & n. 10 & Janeiro - Julho 2017 & p. 265-269 \\
\hline
\end{tabular}

